\title{
TEORIA DA JUSTIÇA DE JOHN RAWLS: ENTRE O LIBERALISMO E O COMUNITARISMO
}

\author{
Denis Coitinho SILVEIRA ${ }^{1}$
}

- RESUMO: O objetivo do presente artigo é realizar uma análise da teoria da justiça como eqüidade de John Rawls em A Theory of Justice e no Political Liberalism, destacando seu modelo de complementaridade entre o deontológico e o procedimental com o teleológico e substancial, buscando responder algumas das críticas levantadas por autores comunitaristas à teoria rawlsiana de justiça e procurando apontar para suas semelhanças. Parto das críticas dos comunitaristas à teoria da justiça como eqüidade; posteriormente, analiso os aspectos teleológicos contidos em seu modelo deontológico; em seguida, destaco a intrínseca relação entre o procedimental e o substancial; por fim, apresento as respostas às críticas comunitaristas à Rawls, destacando a especificidade de sua concepção de justiça.

- PALAVRAS-CHAVE: justiça como eqüidade, deontológico/teleológico, procedimental/substancial, John Rawls.

\section{Introdução}

A teoria da justiça como eqüidade foi apresentada por John Rawls em 1971, com a publicação da obra A Theory of Justice, que estabeleceu um novo marco em filosofia política na segunda metade do século XX, no mundo ocidental. Sua teoria da justiça como eqüidade parte de um pressuposto ético motivacional, com a pergunta pelas razões para o compromisso enquanto membro de uma comunidade moral, defendendo a tese da co-originalidade de liberdade (liberty) e igualdade (equality) em uma sociedade marcada pelo pluralismo razoável (reasonable pluralism) de doutrinas

1 Professor Adjunto do Departamento de Filosofia da Universidade Federal de Pelotas (UFPel). Artigo recebido em mar/07 e aprovado para publicação em jun/07. 
abrangentes (compreensive doctrines), visando fornecer uma orientação filosófica e moral para as instituições democráticas.

Os comunitaristas, como Michael Sandel, Michel Wazer, Alasdair MacIntyre e Charles Taylor, tendem a interpretar a teoria da justiça como eqüidade como deontológica, procedimental, universalista (abstrata) e que estabelece a prioridade do justo sobre o bem. Estas críticas comunitaristas a Rawls estão situadas no debate liberalismo-comunitarismo (the liberalcommunitarian debate) ambientados na década de 80 e que tiveram início após a publicação de A Theory of Justice, que propiciou um novo modelo de teoria da justiça para a filosofia política, gerando fortes críticas tanto dos libertarianos, como Nozick, ou dos igualitaristas, como Dworkin, bem como dos comunitaristas. ${ }^{2}$ As críticas dos comunitaristas à teoria da justiça de Rawls podem ser sintetizadas em cinco teses, a saber: 1) opera com uma concepção abstrata de pessoa que é conseqüência do modelo de representação da posição original sob o véu da ignorância; 2) utiliza princípios universais (deontológicos) com a pretensão de aplicação em todas as sociedades, criando uma supremacia dos direitos individuais em relação aos direitos coletivos; 3) não possui uma teoria da sociedade em função de seu contratualismo, trazendo como conseqüência uma atomização do social, em que a pessoa é considerada enquanto átomo isolado; 4) utiliza a idéia de um Estado neutro em relação aos valores morais, garantindo apenas a autonomia privada (liberdade dos modernos) e não a autonomia pública (liberdade dos antigos), estando circunscrita a um subjetivismo ético liberal; 5) é uma teoria deontológica e procedimental, que utiliza uma concepção ética antiperfeccionista, estabelecendo uma prioridade absoluta do justo em relação ao bem.

Meu objetivo é apontar que essas críticas podem ser facilmente respondidas, evidenciando que a teoria da justiça como eqüidade utiliza alguns mecanismos e pressupostos encontrados em modelos teleológicos/ substanciais, a saber: possui uma concepção deontológica com grandes características teleológicas, na qual o justo e o bem são complementares; está circunscrita a uma concepção substancial de justiça, não sendo apenas procedimental; seu universalismo não se fundamenta no idealismo transcendental, pois não determina a priori os seus princípios de justiça, com a intenção de apontar para os aspectos aproximativos entre comunitaristas e liberais. Para tanto, parto das críticas realizadas pelos comunitaristas à teoria da justiça como eqüidade; posteriormente, analiso os aspectos teleológicos contidos em seu modelo deontológico; em seguida, destaco a intrín-

2 Ver a análise das principais críticas feitas à teoria da justiça de Rawls realizada por Munoz-Dardé, 2000 . 
seca relação entre o procedimental e o substancial em sua teoria; por fim, apresento as respostas às críticas comunitaristas à Rawls, destacando a especificidade de sua concepção de justiça.

\section{Críticas dos Comunitaristas à Teoria da Justiça de Rawls}

Para os comunitaristas, os liberais (universalistas) estariam simplesmente preocupados com a questão de como estabelecer princípios de justiça que poderiam determinar a submissão voluntária de todos os indivíduos racionais, mesmo de pessoas com visões diferentes sobre a vida boa. O que se estabelece como crítica é que, para os comunitaristas, os princípios morais só podem ser tematizados a partir de sociedades reais, a partir das práticas que prevalecem nas sociedades reais (Kukathas \& Pettit, 1990, p.111). ${ }^{3}$ Para eles, em John Rawls, encontram-se premissas abstratas de base como a liberdade e a igualdade que orientam (ou devem orientar) as práticas legítimas. A questão colocada é que, na interpretação comunitarista, a prática tem precedência sobre a teoria, e não seria plausível que pessoas que vivem em sociedades reais identifiquem princípios abstratos para sua existência (cf. Mulhall \& Swift, 2003, p.460). A crítica comunitarista aponta como insuficiente a tentativa de identificar princípios abstratos de moralidade através dos quais sejam avaliadas as sociedades existentes. A questão-chave é a negação de princípios universais de justiça que possam ser descobertos pela razão, pois, em sua avaliação, as bases da moral não são encontradas na filosofia, e, sim, na política. Os comunitaristas criticam o esquema contratualista da teoria da justiça de Rawls que procura compreender as estruturas da sociedade de uma forma idealizada. Também criticam a idéia de uma justiça procedimental que, de forma independente, possa oferecer uma base suficiente para as instituições sociais (cf. Itxaso, 1998, p.290). Para os comunitaristas, só é possível o estabelecimento de leis e regras para as instituições a partir de uma análise da tradição da comunidade e da moral efetivada por essa comunidade para a identificação de valores que podem ser aceitos por todos.

As principais críticas dos comunitaristas à teoria da justiça como eqüidade de John Rawls podem ser agrupadas em cinco teses que problematizam determinados aspectos do pensamento liberal. Em primeiro lugar, criticam a concepção abstrata de pessoa que seria conseqüência do modelo de representação da posição original sob o véu da ignorância, em que terse-ia a distinção entre a pessoa e suas concepções de bem. Para os comu-

3 Sobre debate entre os comunitaristas e os liberais ver o trabalho de Avineri \& de-Shalit, 2001. 
nitaristas a pessoa não pode possuir realidade de forma independente de sua concepção de bem, em função de ela ser constitutiva da identidade pessoal. ${ }^{4}$ Uma segunda crítica se dirige à universalidade dos princípios da justiça na teoria da justiça como eqüidade de Rawls, na qual esses princípios deontológicos teriam a pretensão de aplicação em todas as sociedades e trariam, por conseqüência, a predominância dos direitos individuais em relação aos direitos sociais. ${ }^{5}$ Os comunitaristas criticam a pretensão de universalidade do liberalismo e apresentam como alternativa uma proposta multiculturalista que evidenciaria que diferentes culturas incluem uma diversidade de valores e diferentes formas sociais e institucionais. Em terceiro lugar, criticam a concepção individualista e atomizada de pessoa na teoria da justiça como eqüidade, o que impediria a existência de uma teoria da sociedade no esquema procedimental contratualista (posição original sob o véu da ignorância), o que traria, por conseguinte, uma atomização do social. ${ }^{6}$ Os comunitaristas identificam a matriz social a partir de um ponto de visto sócio-filosófico, como sendo a responsável pela formação de uma concepção de bem e, dessa maneira, criticam o ponto de vista liberal em que a

4 Este é o problema central apresentado por Michael Sandel, a saber, a teoria da justiça como eqüidade de Rawls opera com uma concepção de sujeito moral como um eu completamente dissociado de suas experiências contingentes. Para Sandel, uma pessoa com essas características seria incapaz de realizar escolhas morais, porque lhe faltariam a experiência e a motivação, invalidando sua capacidade de escolha. A concepção de pessoa que está contida na posição original não dá conta de inserir referências ao mundo empírico, revelando uma concepção de sujeito completamente desencarnado, sendo uma concepção formal, abstrata e distanciada das contingências e, sendo assim, incapaz de identificar as motivações necessárias (Sandel, 1982, p.20-8).

5 Essa crítica é estabelecida principalmente por Michael Walzer em seu livro Spheres of Justice, apontando que toda teoria da justiça que se pretende filosófica e na qual se percebe a presença do filósofo que sai da caverna para descobrir princípios universais incorre em um fundamental erro, pois não respeita a cultura própria de uma comunidade política, criando um mecanismo artificial que não condiz com a realidade política da comunidade real. Para Walzer, a teoria de justiça rawlsiana erra quando pretende que as práticas da comunidade política sejam examinadas a partir da razão abstrata do filósofo e pensadas a partir de padrões abstratos e utópicos por ele construídos e identificados como princípios (Walzer, 1983, p.15-6).

6 O que está em questão é uma forte crítica a uma concepção individualizada e atomizada de pessoa, em que os direitos individuais estariam acima dos interesses da sociedade. Para Charles Taylor, as teorias liberais de justiça, em especial a teoria da justiça como eqüidade de Rawls, ao afirmarem a prioridade na escolha de fins por parte dos indivíduos, estariam afirmando os direitos individuais em sobreposição aos direitos da sociedade. Essa interpretação ressalta que a teoria liberal concebe a pessoa atomisticamente, sendo incapaz de explicar de forma adequada a questão da sociabilidade humana. A questão apontada é que o cerne das teorias liberais encontra-se nos direitos individuais e, sendo assim, as instituições liberais não possuem capacidade de avaliação da importância do apoio em relação às capacidades humanas que tornam possível a escolha individual. Para Taylor, as instituições deveriam estar preocupadas em garantir que o contexto social e político sirva de modelo para auxiliar no desenvolvimento das capacidades que possibilitam a escolha individual (Taylor, 1985, p.187-210). 
sociedade seria vista como uma aventura cooperativa para o benefício individual, em que a sociedade é interpretada como uma associação privada formada por indivíduos que possuem interesses de maneira independente da comunidade. Uma quarta crítica é endereçada ao subjetivismo ético contido na teoria de Rawls que operaria com a idéia de um Estado neutro com respeito aos valores morais, garantindo apenas a liberdade de expressão dos indivíduos, isto é, a capacidade de decidir livremente e perseguir racionalmente uma certa concepção de bem. ${ }^{7} \mathrm{O}$ contraponto oferecido pelos comunitaristas destaca que o Estado não deve ser neutro em relação a uma hierarquização dos valores, tendo a tarefa de fomentar esses valores, promovendo a virtude através da educação e excluindo os piores valores. Por último, a teoria da justiça como eqüidade de Rawls é interpretada como somente procedimental e deontológica, na qual imperaria uma neutralidade do Estado e das leis, com uma concepção ética antiperfeccionista, que estabelece uma prioridade absoluta do justo em relação ao bem. ${ }^{8}$ A crítica comunitarista aponta a impossibilidade de separação entre a esfera pública, que operaria com critérios unitários, e a esfera privada, que resguardaria a prática das distintas concepções morais, em função de que determinadas visões morais incluem como parte dessa ética uma visão global do indivíduo, não podendo distinguir as concepções éticas das atuações e escolhas públicas (cf. Ramos, 1998, p.235).

\section{Modelo Deontológico/Teleológico}

O objetivo de Rawls é elaborar uma teoria da justiça como eqüidade que se apresente como alternativa ao utilitarismo em suas diversas versões (Rawls, 2000, p.25). Como, na teoria utilitarista, o bem se define de maneira independente do justo, esta teoria é caracterizada como teleológica e, no, contratualismo de Rawls, seu objetivo é estabelecer a prioridade do justo

7 Esta crítica é realizada por Alasdair MacIntyre, em After Virtue, afirmando que não é possível esperar que a investigação a respeito das estruturas sociais aconteça a partir de um ponto de vista desinteressado e imparcial e afastado da comunidade, e que isto possa servir como paradigma com valor moral positivo. A questão é a afirmação de uma razão prática como uma atividade ordenada que leve em consideração a perspectiva da comunidade que compartilha crenças sobre bens e disposições inseridos em práticas compartilhadss comumente (cf. MacIntyre, 1985, p.426-7).

8 Para MacIntyre, a teoria da justiça como eqüidade de Rawls não contribui em nada com o objetivo de reconstrução da comunidade, insistindo em um projeto que está condenado ao fracasso absoluto, isto é, a um projeto que está centrado em um indivíduo racional atomizado que se sobrepõe à sociedade, em que os interesses individuais antecedem ao estabelecimento de laços morais entre si, sendo independente dessa criação, o que implica assumir uma ética antiperfeccionista que impõe uma prioridade do justo sobre o bem (cf. MacIntyre, 1985, p.419). 
em relação ao bem, a teoria da justiça como eqüidade se identifica como deontológica. O que é importante demonstrar é que a teoria teleológica que se mostra distante de forma absoluta da teoria da justiça como eqüidade é o utilitarismo clássico, isto é, o contraponto que é estabelecido por Rawls quer analisar as diferenças substanciais das duas doutrinas. Dessa forma, é possível analisar as semelhanças da teoria da justiça como eqüidade com outros modelos teleológicos, revelando que esta teoria não é puramente deontológica, como é apresentada em seu modelo clássico, pois pressupõe elementos teleológicos como, por exemplo, o conseqüencialismo.

Rawls procura formular uma concepção de justiça como eqüidade (justice as fairness) colocando a eqüidade como base articuladora da justiça, tendo como objetivo central superar a debilidade teórica da filosofia moral predominante no mundo anglo-saxão, combatendo principalmente a tese utilitarista que prioriza o bem em relação ao justo. O resultado será uma teoria moral deontológica e não-naturalista, uma teoria que estabelece a prioridade do justo (right) sobre o bem (good), capaz de dar um fundamento filosófico a esse dever ou à noção de justiça que deve ser ontologicamente anterior a qualquer concepção empírica do bem. Sua proposta é estabelecer uma concepção de justiça que generalize e eleve a um plano superior a teoria contratualista de Locke, Rousseau e Kant, estabelecendo um construtivismo de tipo kantiano. O papel da justiça é especificar os direitos e deveres básicos dos cidadãos e determinar as partes distributivas apropriadas, sendo a justiça a virtude mais importante das instituições sociais, significando que cada pessoa possui uma inviolabilidade normativa fundada na justiça (idem, p.3). O objetivo primário da justiça é a estrutura básica da sociedade, isto é, a forma pela qual as instituições sociais (constituições e acordos) distribuem direitos e deveres fundamentais e determinam a divisão de vantagens vindas da cooperação social. O conceito de justiça, então, se define pela atuação de seus princípios na atribuição de direitos e deveres e na definição da divisão apropriada de vantagens sociais, não constituindo conflito com a noção tradicional de justiça (idem, p.10). É possível perceber, inicialmente, que por mais que a intenção de Rawls seja estabelecer uma concepção deontológica em TJ, ele não consegue escapar de uma perspectiva conseqüencialista, em que as conseqüências são fundamentais para a valoração moral de um ato, distinguindo-se de uma visão estritamente deontológica, na qual as conseqüências não são levadas em consideração para o estabelecimento do valor moral de uma ação, por basear-se somente em critérios absolutos. Esse conseqüencialismo, que está associado a uma perspectiva teleológica, é percebido na justiça como eqüidade no momento em que se compreende a justiça como a virtude mais importante das instituições sociais e se identifica a estrutura básica como objeto da justiça e não a correção ou incorreção moral de conduta dos agentes parti- 
culares, estabelecendo uma relação necessária com as conseqüências ou os efeitos que as várias configurações institucionais possuem para a distribuição de benefícios e encargos (direitos e deveres) na sociedade, constituindo-se como uma teoria "conseqüencialista-contratual". ${ }^{9}$

Rawls propõe uma teoria contratualista (que opera em um plano mais abstrato que as teorias contratualistas clássicas), apresentando uma concepção de justiça que surge de um consenso original e estabelece princípios para a estrutura básica da sociedade. Em uma posição original de igualdade, pessoas livres e racionais que têm a preocupação de promover seus interesses aceitam princípios como definidores dos termos básicos de sua associação. Esses princípios têm a função de regular todos os acordos, bem como as formas de governo e os tipos de cooperação social, e é essa maneira de interpretar os princípios da justiça que é identificada com a justiça como eqüidade. A concepção exposta por Rawls é a da justiça como eqüidade, que opera com uma noção pública da justiça específica de uma sociedade bem-ordenada. O que significa encontrar princípios defensáveis por um conjunto de seres racionais em uma situação de igualdade inicial, pois só a partir da igualdade, esses seres racionais serão capazes de se colocarem de acordo e decidirem imparcialmente. E é essa imparcialidade, eqüidade (fairness), o que define propriamente a justiça. Dessa forma, os indivíduos chamados a optar por uma idéia de justiça serão seres racionais e mutuamente desinteressados. Estarão dispostos a perseguir os fins, especificando os meios para alcançá-los, e capazes de atuar sem buscar unicamente a satisfação de seus interesses privados, capazes de se comprometerem na elaboração de um ideal de justiça. O que está em jogo é apresentar um modelo procedimental de representação, uma situação imaginária de imparcialidade, em que não entrem em ação referências contingentes. Em uma posição original (original position), os princípios de justiça são escolhidos sob o véu da ignorância (veil of ignorance), em que ninguém conhece as condições particulares. Ninguém conhece o seu lugar na sociedade, a posição de sua classe ou status social, sua sorte na distribuição de habilidades naturais, sua inteligência, força etc. Conhecem apenas algo tão impreciso como as bases elementares da organização social e da psicologia humana. As pessoas, sob o véu da ignorância, escolhem os princípios de justiça como resultado de um consenso ou ajuste eqüitativo. As partes que entram em consenso na posição original, sob o véu da ignorância, são racionais e desinteressadas (não possuindo interesse no interesse das outras) e, sendo assim, não podem escolher um princípio utilitário porque não garan-

9 Sobre o papel do conseqüencialismo na teoria da justiça como eqüidade ver Pogget, 1995, p.253 e Vita, 2000, p.32-3. 
tiria vantagens e/ou direitos para uma minoria em benefício de uma maioria. As partes escolheriam, então, dois princípios. O primeiro princípio escolhido seria aquele que exigiria a igualdade na atribuição de deveres e direitos básicos, assegurando, assim, a liberdade. O segundo princípio escolhido seria aquele que afirmaria que as desigualdades econômicas e sociais, como desigualdade de riqueza e autoridade, são justas se resultarem em benefícios para cada um e especialmente para os membros menos favorecidos da sociedade, sendo que esses princípios possuem uma ordem lexográfica entre eles (Rawls, 2000, p.53; TJ §11). Mas, por que as partes não poderiam escolher um princípio utilitário que não garantiria vantagens e/ou direitos para uma minoria em benefício de uma maioria e por que escolheriam o segundo princípio, que estabelece que as desigualdades são justas se resultarem em um aumento de vantagens para os menos favorecidos? Parece ser provável que, em uma situação de incerteza, a escolha do ponto de vista racional utilizasse o princípio da utilidade, que afirma que a ação é válida moralmente se maximizar o que é o bem (felicidade, bem-estar, preferências). ${ }^{10} \mathrm{O}$ que as leva à negação do princípio utilitário e à afirmação do princípio da diferença é o pressuposto de uma ética das virtudes, que considera a igualdade dos seres humanos como pessoas éticas, que têm uma concepção de bem e senso de justiça, ${ }^{11}$ isto é, na posição original, estão pressupostas premissas morais que não podem ser apagadas (escondidas) pelo modelo procedimental contratualista pretendido, a saber: um critério forte de igualdade moral e um pressuposto motivacional de que é possível agir segundo um senso de justiça. ${ }^{12}$

Já na posição original, sob o véu da ignorância, as pessoas que escolhem os princípios de justiça para orientar a estruturação social possuem ponderadas convicções sobre a justiça (our considered convictions of justice) (Rawls, 2000, p.18; TJ §4). ${ }^{13}$ Essas convicções sobre a justiça já estão pressupostas - mesmo na posição original sob o véu da ignorância - bas-

10 Segundo Harsany, na posição original sob o véu da ignorância, a melhor escolha racional em condições de incerteza deve encontrar-se em um princípio de maximização da utilidade média e não o princípio da diferença defendido por Rawls. Ver Harsany, 1995, p.594-606.

11 TJ §3, p.11: "For given the circumstances of the original position, the symmetry of everyone's relations to each other, this initial situation is fair between individuals as moral persons that is as rational beings with their own ends and capable, I Shall assume, of a sense of justice.

12 Clark Wolf interpreta que as duas faculdades morais (senso de justiça e concepção de bem) são elementos cruciais para a concepção de cidadãos como livres e iguais, sendo que a capacidade de senso de justiça é necessária para possibilitar a cooperação social. Ver Wolf, 2000, p.105.

13 Na interpretação de Kenneth Baynes, a posição original não representa a situação de escolha baseada simplesmente em uma noção neutra de racionalidade, e isto porque ela pressupõe uma concepção de sociedade bem-ordenada (well-ordered society) e pessoa (person) que possui uma compreensão do que é justo. Ver Baynes, 1992, p.125-35. 
tando agora a teoria da justiça definir a regra que efetive a justiça. ${ }^{14}$ Aceitar os princípios de justiça equivale a subscrever uma determinada noção de bem comum, pois o que obriga a estabelecer certos procedimentos específicos, visando garantir a eqüidade é uma determinada compreensão da vida humana e, portanto, uma concepção de bem. ${ }^{15}$ Na posição original, sob o véu da ignorância, dá-se por pressuposto o direito dos bens primários (primary goods) (liberdades fundamentais, oportunidade, renda, riqueza e auto-respeito), já que estes constituem as condições necessárias para que as diferenças pessoais cheguem a satisfazer suas diversas concepções de bem (Rawls, 2000, p.78-81; TJ §15). ${ }^{16}$ Os bens primários são aceitos sobre a base de uma determinada concepção de personalidade moral, a qual subjaz à noção de justiça como eqüidade. ${ }^{17}$ Revela-se, assim, a finalidade específica do equilíbrio reflexivo (reflective equilibrium), que é uma situação de avanços e recuos na posição original, em que se estabelecem os princípios e consensos acerca do bem, estabelecendo um diálogo permanente entre os princípios e os juízos particulares (Rawls, 2000, p.18; TJ §4).

Evidencia-se que a proposta de John Rawls é deontológica, pois não especifica o bem de maneira independente do justo ou não interpreta o justo como maximizador do bem. Sua proposta é construir uma teoria procedimental de justiça. As partes envolvidas na posição original não se movem a partir de uma concepção prévia de dever ou justiça. A justiça é o resultado imediato de um procedimento, sendo uma justiça procedimental pura (pure procedural justice). Entretanto, as pessoas são movidas pelo interesse moral, pela capacidade de serem eqüitativos, interesse esse que se faz específico na formulação de bens primários, em que está pressuposto que todos têm direito a uma igual parcela dos bens primários produzidos em uma so-

14 Adina Schwartz defende o posicionamento que a teoria da justiça como eqüidade é mais teleológica do que Rawls gostaria de admitir. Isto porque há premissas teleológicas que subjazem à posição original sob o véu da ignorância, como se mostra pela presença dos juízos particulares de justiça (our judgments of justice) no método do equilíbrio reflexivo (reflective equilibrium). Schwartz, 1973, p.294-8.

15 Charles Taylor defende a idéia de que toda teoria que estabelece a prioridade do justo em relação ao bem, encontra-se fundamentada em uma concepção de bem, pois o que estabelece a obrigatoriedade de estabelecer certos procedimentos é uma certa compreensão da vida humana em uma doutrina antropológica e, sendo assim, em uma concepção específica de bem (Taylor, 1988, p.33-56)

16 Stéphane Chauvier aponta que o motivo para introduzir uma noção como a de bens primários possui uma dupla exigência de neutralidade e de compatibilidade com a responsabilidade individual que pesa sobre a teoria liberal de justiça social. Ver Chauvier, 2004, p.70.

17 Paul Ricoeur defende a idéia de que a teoria deontológica usada por Rawls não é desprovida de perspectivas teleológicas, pois na posição original, embora não se saiba sobre sua concepção de bem, já se sabe que os indivíduos preferem ter mais bens sociais em relação a ter menos. Ver em Ricoeur, 1990, p.557. 
ciedade. Aqui, percebe-se claramente o limite de uma teoria de justiça procedimental, em função de, na justiça como eqüidade, se reconhecer a necessidade de uma precompreensão de bem ou dos bens que a sociedade vai distribuir. A posição original é o local no qual se concordam com princípios que proporcionam que os bens sejam repartidos de forma justa, eqüitativa, e tem como pressuposto essencial uma ponderada convicção sobre a justiça, que garante bens como a liberdade, a vida, a igualdade e bens sociais mínimos para a sobrevivência, assumindo claramente um caráter igualitário, inserindo, de uma certa maneira, algum conteúdo no esquema formal (deontológico), operando uma complementaridade entre o justo e o bem. ${ }^{18}$ Esta aproximação em direção a um modelo teleológico serve, também, para objetar a respeito de interpretações que têm por objetivo a associação da teoria da justiça como eqüidade com as teorias utilitaristas, que identificam a escolha dos princípios da justiça na posição original com o desejo racional de satisfação individual.

\section{Modelo Procedimental/Substancial}

Em TJ §87, no qual Rawls procura fazer alguns comentários finais a respeito de sua teoria da justiça como eqüidade, identifica, como sua intenção, desenvolver uma teoria substantiva de justiça (Rawls, 2000, p.507; TJ $\S 87)$. A questão colocada é procurar identificar as características fundamentais da justiça como eqüidade, demonstrando a discordância com as teorias éticas que se utilizam da justificativa cartesiana (dedutiva) ou da justificativa naturalista. Rawls destaca que a obra TJ foi dividida em três partes (Theory - Teoria, Institutions - Instituições e Ends - Objetivos) e que cada parte propiciou apoio à outra, dando uma idéia de todo ordenado. $\mathrm{Na}$ primeira parte (Theory), acontece a apresentação dos elementos essenciais da estrutura teórica e a argumentação em favor dos princípios da justiça com base em estipulações razoáveis em razão da escolha dessas concepções. Na segunda parte (Institutions), Rawls examinou os tipos de instituiÇões prescritas pela justiça como eqüidade e os tipos de deveres e obrigações que ela impõe. A terceira parte (Ends) verifica se a justiça como eqüidade é uma concepção viável, obrigando à investigação sobre a estabilidade e sobre a relação entre o justo e o bem (idem, p.506-14; TJ §87). Rawls confirma que essas considerações não determinam o reconhecimento inicial dos princípios, mas o confirmam, em função de mostrar que a natureza

18 Ver o texto de Samuel Freeman sobre a congruência do direto (right) e bem (good) e seus limites em "Congruence and the Good of Justice" (Freeman, 2003, p.277-315). 
humana permite que a escolha original seja implementada, abrindo espaço para uma interpretação moral da natureza humana (idem, p.514; TJ §87).

Em Political Liberalism IV, 7 (doravante indicado como PL), Rawls analisa a passagem de um consenso constitucional (constitutional consensus) para um consenso sobreposto (overlapping consensus). A profundidade (depth) de um consenso sobreposto determina que seus princípios e ideais políticos tenham por base uma concepção política de justiça que faça uso das idéias fundamentais de sociedade e pessoa da forma especificada pela justiça como eqüidade. A extensão (breadth) do consenso sobreposto obriga a esses princípios irem além da abrangência dos princípios políticos no horizonte de procedimentos democráticos, estabelecendo certos direitos substantivos (substantives rights), como a liberdade de consciência e pensamento, igualdade eqüitativa de oportunidades e princípios que atendam às necessidades básicas (Rawls, 1996, p.164; PL IV, 7.1). Para Rawls, um consenso constitucional é "restrito demais" (too narrow), em função de ser um consenso puramente político e procedimental que não terá possibilidade de promulgar uma legislação que abordará os fundamentos constitucionais e as questões de justiça básica. Aqui, revela-se a importância da extensão do consenso sobreposto que estabelece uma legislação que garante a liberdade de consciência (liberty of conscience) e pensamento (freedom of thought generally), a liberdade de associação (freedom of association) e movimento (freedom of movement) e a satisfação das necessidades básicas dos cidadãos (basic needs of all citizens), garantindo a participação na vida política e social (idem, p.166; PL IV, 7.3). ${ }^{19}$ Essa abordagem do consenso sobreposto a respeito de sua profundidade, extensão e especificidade revela que a justiça como eqüidade utiliza-se de princípios substanciais de justiça e não somente de princípios que respeitam o procedimento justo. ${ }^{20}$

Em PL V, 5, Rawls ressalta que a justiça como eqüidade não é neutra no sentido procedimental (is not procedurally neutral), pois seus princípios de justiça são substantivos e expressam mais que valores puramente proce

19 Em Justice as Fairness (JF), Rawls trata da noção de consenso sobreposto e conclui afirmando que (1) não há garantia de que a justiça como eqüidade possa alcançar o apoio de um consenso sobreposto, dadas as visões abrangentes existentes em sociedade, mas (2) quer articular uma concepção de justiça para um regime constitucional que seja defensável em si mesma e também que possa ser endossada por todos (JF I, §11, p.37-8). Rawls, 2001

20 Brian Barry defende o argumento de uma circularidade não-viciosa em Rawls, em que o critério da aceitabilidade razoável de princípios confere uma certa substância à idéia de igualdade fundamental ao mesmo tempo em que deriva dessa mesma idéia. É a idéia de uma sociedade bemordenada como sendo aquela que a igualdade humana fundamental é reconhecida pela partes. Ver Barry, 1995, p.8. 
dimentais (procedural values). ${ }^{21}$ Fica ressaltado que a forma de neutralidade da justiça como eqüidade não pode ser confundida com algumas formas de liberalismos que defendem uma neutralidade por não utilizarem nenhuma idéia do bem, somente as puramente instrumentais. A justiça como eqüidade pretende ser objeto de um consenso sobreposto, a saber, como um todo pretende articular uma base pública de justificação para a estrutura básica de uma sociedade bem-ordenada, partindo de idéias que estão subjacentes à cultura pública e abstraindo as doutrinas abrangentes. Seu objetivo é encontrar um terreno comum, um terreno neutro político como objetivo de um consenso sobreposto. Rawls considera que a justiça como eqüidade pode encorajar certas virtudes morais como as de tolerância, senso de justiça e razoabilidade e afirmar a superioridade de certas formas de caráter moral (idem, p.194; PL V, 5.4). A questão que já tinha sido identificada por Rawls é que as idéias de bem podem ser introduzidas para a complementação da concepção política de justiça, desde que essas idéias de bem sejam políticas, isto é, desde que estejam identificadas com uma concepção política razoável de um regime constitucional. Essas virtudes morais associadas às idéias de bem estão vinculadas aos princípios de justiça política e, sendo assim, são compatíveis com o liberalismo político. Essa concepção de regime constitucional que favorece a tolerância, desencorajando as discriminações religiosas ou sociais não assume a forma de um Estado perfeccionista. Esse Estado se vale de medidas razoáveis para fortalecer as diversas formas de sentir e pensar que dão sustentação à cooperação social eqüitativa entre seus cidadãos livres e iguais (idem, p.195; $P L \mathrm{~V}, 5.4$ ). Entretanto, podemos perceber que essa concepção de Estado que assume certas virtudes político-morais não pode ser confundida com a interpretação do liberalismo clássico de um Estado mínimo. A justiça como eqüidade assume certas virtudes políticas para a garantia da eqüidade social, demonstrando, assim, a substancialidade de seus princípios e, também, a aproximação a uma ética das virtudes. ${ }^{22}$

$21 P L$ V, 5.3, p.192: "Justice as fairness is not procedurally neutral. Clearly its principles are substantive and express far more than procedural values, and so do its political conceptions of society and person, wich are represented in the original position".

22 Analisando a circularidade de TJ, em que, nas partes da Theory e Institutions, utiliza-se da justiça como princípio e, na parte que trata dos Ends, trata da justiça como virtude, percebe-se uma circularidade que aponta para uma aproximação entre a ética deontológica e a ética das virtudes. Isso porque o princípio da justiça passa a ser compreendido enquanto uma virtude moral, entretanto, esta virtude não vai além de sua função orientadora, o que não resulta em uma fundamentação tradicional da esfera da justiça. Creio que é possível pensar em uma complementaridade entre uma ética dos princípios e uma ética das virtudes, interpretando a virtude moral como uma outra face do princípio moral que possui a função de lhe confirmar a validade. 
Em PL VII, 9, Rawls adverte da importância de incorporar uma forma ideal para a estrutura básica (basic structure), além do elemento de justiça procedimental pura, para a determinação das partes distributivas de maneira eqüitativa (idem, p.281; PL VII, 9). Uma questão essencial, então, é investigar a respeito do papel específico da estrutura básica, a saber, a partir de qual princípio as pessoas morais livres e iguais podem aceitar a argumentação de que as desigualdades sociais e econômicas decorrem da boa ou má sorte ou das contingências históricas e naturais? A resposta apresentada é que as partes, como pessoas morais, livres e iguais, partirão da suposição de que todos os bens primários, como renda e riqueza, deveriam ser iguais, levando em consideração os requisitos organizacionais e a eficiência econômica. A partir desse raciocínio, não seria justo (ou razoável) se contentar com uma divisão igual. A estrutura básica, então, deve permitir desigualdades econômicas e organizacionais, considerando-se que estas desigualdades melhorem a situação de todos, especialmente a situação dos menos privilegiados, desde que as desigualdades sejam uma coerência com a liberdade igual e a igualdade eqüitativa de oportunidade (idem, p.282; PL VII, 9). Sendo a divisão igual o ponto de partida, os que estão em uma situação em que menos se beneficiam possuem um poder de veto. Dessa maneira, as partes chegam ao princípio da diferença. Para a compreensão do princípio da diferença, é importante destacar, que os dois princípios de justiça, quando operam juntos, incorporam um elemento fundamental de justiça procedimental pura na repartição das parcelas distributivas. Esta é a insuficiência e o limite da justiça procedimental pura, pois não estabelece o que é o seu conteúdo distributivo, não estabelecendo o que deve ser objeto de distribuição (idem, p.283; PL VII, 9). Em função desse raciocínio, temos que os princípios de justiça, e, em especial, o princípio da diferença, aplicam-se aos princípios públicos e às políticas mais importantes que regulam as desigualdades sociais e econômicas. ${ }^{23}$ Os princípios de justiça não exigem a distribuição igual, mas revelam a idéia basilar que ninguém deve possuir menos do que receberia numa divisão igual de bens primários e, também, que, quando a cooperação social possibilitar uma melhora em termos gerais, as desigualdades que existem devem beneficiar aqueles que estão em uma situação mais desfavorecida, tendo por base de referência a divisão igual. ${ }^{24}$ Os princípios de justiça têm a finalidade de es-

23 A aplicação do princípio da diferença acontece na tributação de renda e propriedade, na política fiscal e econômica e no contexto institucional (direito público, normas legais) das transações específicas. Ver Van Parijs, 2003, p.200-40).

24 Este é o argumento utilizado por Scanlon que aponta que a tese central do princípio da diferença constitui-se na idéia de que as instituições básicas da sociedade possuem uma base cooperativa, tomando os cidadãos como parceiros iguais (Scanlon, 1989, p.204). 
pecificar uma forma ideal para a estrutura básica, forma essa que restringirá e ajustará os processos institucionais e procedimentais. ${ }^{25}$ Essa análise a respeito do papel dos princípios de justiça nos aponta, novamente, para os limites de uma teoria puramente procedimental de justiça, que não contém princípios estruturais para uma ordem social justa e, assim, não oportuniza um critério mais forte que tenha como objetivo político eliminar a injustiça e esclarecer a respeito das mudanças para uma estrutura básica justa da sociedade. Essa é a defesa do ponto de vista de uma justiça substancial, em que se percebe a especificação dos princípios estruturais fundamentais, apontando os elementos essenciais da ação política, que servem como fundamentação racional da eqüidade social. ${ }^{26}$ Essa interpretação do papel forte dos dois princípios de justiça, que devem garantir os bens sociais primários para a estrutura básica da sociedade, revela o aspecto substantivo da justiça como eqüidade e demonstra a idéia que uma teoria procedimental de justiça não é autônoma, contribuindo para a efetivação de um sentido substancial de justiça que está pressuposto.

É de fundamental importância fazer referência ao texto Replay to Habermas (doravante indicado como $R H$ ), em que, na quinta parte, Rawls debate com Habermas a respeito da questão da justiça procedimental versus justiça substantiva, esclarecendo seu posicionamento de defesa de uma concepção liberal substantiva de justiça. Habermas, depois de estabelecer as objeções ${ }^{27}$ a alguns aspectos da realização do projeto rawlsiano, tece algumas considerações a respeito do contraponto entre a justiça procedimental em relação à justiça substancial. Habermas propõe uma teoria procedimental da moral e do direito limitada aos aspectos procedimentais do uso público da razão que desenvolve o sistema de direitos a partir da idéia de sua institucionalização jurídica. Habermas propõe que a filosofia se limite ao esclarecimento do ponto de vista moral e do procedimento democrático

25 A teoria da justiça como eqüidade se ocupa dos princípios que vão orientar a estrutura básica da sociedade e não as escolhas de nível privado, princípios esses que se constituem como objeto de uma teoria de justiça social.

26 PL VII, 9, p.285: "A purely procedural theory that contained no structural principles for a just social order would be of no use in our world, where the political goal is to eliminate injustice and to guide change toward a fair basic structure. A conception of justice must specify the requisite structural principles and point to the overall direction of political action".

27 Habermas, 1995. A primeira objeção de Habermas é a dúvida se o esquema da posição original é adequado para assegurar a imparcialidade de princípios de justiça deontológicos. Em segundo lugar, destaca que Rawls deveria separar as questões de aceitação. Fica a suspeita de que a neutralidade de sua concepção de justiça política frente às concepções de mundo invalidaria a pretensão de validade cognitiva. Em terceiro lugar, para Habermas, essas duas decisões estratégicas têm como conseqüência uma construção de um Estado de direito que coloca os direitos básicos liberais sobre o princípio democrático de legitimação, invalidando sua tentativa de conciliação entre as liberdades dos modernos e as liberdades dos antigos. 
e à análise das condições do discurso e à negociação racional, de um ponto de vista puramente reconstrutivo; sendo que, as respostas substanciais que precisam ser dadas se deixa a cargo dos participantes, o que não exclui o filósofo de participar da discussão pública no papel de intelectual e não no papel de especialista.

Rawls responde à acusação de Habermas de que a teoria da justiça como eqüidade é substantiva em vez de procedimental. A justiça procedimental estabelece a justiça de um procedimento ou é o procedimento que tem o valor de imparcialidade, enquanto a justiça substantiva espera a justiça de seu resultado. Para Rawls, existe uma conexão entre a justiça procedimental e a substantiva, como se pode observar a partir de dois casos, a saber: no primeiro, teríamos a justiça procedimental perfeita, como procedimento de sentido comum de dividir um pastel (igual divisão); no segundo, teríamos a justiça procedimental imperfeita, como em um juízo criminal, em que nenhum procedimento criminal pode garantir que condena o acusado se, e somente se, o acusado cometeu o crime. Dessa forma, a justiça procedimental depende da justiça substantiva (Rawls, 1996a, p.421; RH §5.1) (cf. Rawls, 1996, p.372-434). Para Rawls, não é possível uma legitimidade procedimental sustentada sobre si mesma, sendo necessária uma justiça substantiva. Os cidadãos, na sociedade civil, não usam a idéia de justiça como eqüidade como uma plataforma, conduzidos pelo filósofo (expert), de onde julgam os ordenamentos e políticas existentes. Os cidadãos têm que possuir algumas idéias do direito e da justiça, possuindo alguma base para a sua reflexão. Segundo Rawls, Habermas considera que sua concepção se limita aos aspectos procedimentais do uso público da razão; pelo uso regular da idéia de legitimidade, mais do que pela idéia de justiça. Rawls chama a atenção para a diferença entre legítimo e justo. Por exemplo, um governante legítimo não garante um governo justo. A legitimidade é uma idéia mais fraca que a idéia de justiça, pois se pergunta pelo procedimento e não pelo resultado; mas, em algum ponto, a injustiça do resultado de um procedimento democrático legítimo corrompe sua legitimidade, trazendo a injustiça. Um procedimento legítimo é um procedimento que todos podem aceitar razoavelmente como livres e iguais enquanto todos têm que tomar decisões coletivas e falta normalmente o acordo. É importante observar, ressalta Rawls, que a legitimidade das legislações depende da justiça da constituição, e quanto maior o desvio em relação à justiça, maior a probabilidade de um resultado injusto, sendo que as leis não podem ser injustas se se pretendem legítimas. Dessa reflexão, conclui-se a necessidade de juízos de justiça substantiva (Rawls, 1996a, p.423-4; RH §5.1).

Habermas acusa a teoria da justiça como eqüidade de ser substancial por incluir a condenação da escravidão, da perseguição religiosa, da subordinação das classes trabalhadoras, da opressão das mulheres, da acumula- 
ção de vastas fortunas, da tortura etc. Não é um problema para Rawls admitir que sua teoria é substantiva e não puramente procedimental (idem, p.431; $R H$ §5.4). A justiça como eqüidade é substantiva por surgir no horizonte da tradição do pensamento liberal das sociedades democráticas, como pertencente ao éthos das comunidades políticas de cultura plural e democrática. ${ }^{28}$ Dessa maneira, a teoria da justiça não pode ser identificada como puramente formal em um âmbito puramente universalista, pois não opera com pressupostos transcendentais, como é a interpretação de Habermas. Como doutrina política, a justiça como eqüidade não quer tomar parte de nenhuma doutrina compreensiva da forma e dos pressupostos estruturais do pensamento e da ação. Prefere deixar essas doutrinas como estão e estabelecer a crítica somente na medida em que não forem razoáveis politicamente (idem, p.432-3; $R H$ §5.4). Com isso, Rawls, respondendo à objeção de Habermas, conclui que não é possível uma legitimidade procedimental de forma auto-sustentada, sendo necessária uma justiça substantiva. Os cidadãos, na sociedade civil, não utilizam a idéia de justiça como eqüidade como plataforma, conduzidos pelo filósofo, de onde julgam os ordenamentos e políticas existentes. Os cidadãos devem possuir algumas idéias do direito e da justiça, possuindo uma base objetiva para sua reflexão. Para Rawls, a legitimidade é uma idéia mais fraca do que a idéia de justiça, pois ao perguntar-se apenas pelo procedimento e não pelo resultado, é possível que a injustiça do resultado de um procedimento legítimo corrompa a legitimidade, efetivando a injustiça. Dessa maneira, não existe nenhum impedimento em admitir que a justiça como eqüidade é substantiva e não puramente procedimental, pois ressalta uma conexão intrínseca entre justiça procedimental e justiça substantiva, a fim de preservar a justiça eqüitativa. ${ }^{29}$

É importante observar que Rawls não utiliza o esquema do idealismo transcendental de Kant em sua posição de construtivismo político (Rawls, 1996, p.99-101; PL III, 2 - Kant's moral constructivism), pois nega o univer-

28 Segundo Álvaro de Vita não é necessário recorrer ao mecanismo contratual da posição original para assegurar a validade dos princípios de justiça em uma sociedade bem-ordenada, mas, que é a própria sociedade bem-ordenada que oferece a validade a respeito dos princípios de justiça através da tradição democrática que oferece consensos básicos a respeito da justiça. Cf. Vita, 1993, p.34-5.

29 Nythamar de Oliveira argumenta na mesma direção, afirmando que o procedimento contratual de inspiração kantiana utilizado por Rawls possibilita a articulação entre uma concepção substantiva de justiça e uma concepção procedimental de justiça a partir da própria concepção de "sociedade democrática liberal", significando a noção de sociedade e de sua estabilidade. Ver em Oliveira, 1999, p.174. É importante ressaltar que a teoria da justiça como eqüidade defende uma cooriginilidade entre a autonomia pública e privada, estabelecendo uma complementaridade entre a liberdade dos antigos e a liberdade dos modernos. 
salismo apriorístico de Kant. O universalismo utilizado por Rawls é consensual (pragmático e não-transcendental), pois se relaciona com a idéia de um consenso sobreposto entre doutrinas abrangentes divergentes, que busca encontrar um minimum político para a coexistência em sociedade que se encontra habitada por diversas concepções de bem, religiões e doutrinas filosóficas, não sendo uma idéia deduzida da razão. ${ }^{30} \mathrm{Em}$ Rawls, percebe-se a utilização de uma razão (racionalidade) mais fraca do que em Kant, isto é, ele se utiliza do razoável (em vez do racional puramente), que procura encontrar acordos consensuais dialógicos, operando com uma razão a posteriori, diferenciando-se da razão apriorística utilizada por Kant. ${ }^{31} \mathrm{O}$ universalismo de Rawls dialoga com premissas particularistas no momento em que pretende desenvolver e articular a noção de justiça contida no senso comum da comunidade democrática, estabelecendo uma complementaridade entre o universalismo e o particularismo. ${ }^{32}$ Vale lembrar que em $R H$, Rawls responde a Habermas que sua teoria não utiliza argumentos quase transcendentais como é percebido na teoria do agir comunicativo habermasiana, não situando seu pensamento em um universo puramente formal e universal no sentido transcendental, defendendo uma concepção "freestanding" de justiça (Rawls, 1996a, p. 373-85; RH §1).

O liberalismo político de Rawls é uma doutrina que pertence ao âmbito do político, sendo uma teoria da justiça como eqüidade, isto é, uma concepção política liberal de justiça para um regime democrático que pode ser aceito por todas as doutrinas compreensivas razoáveis existentes em uma democracia, tratando somente do político, possuindo uma fundamentação de caráter puramente político-filosófico, afastando-se de um fundacionalismo metafísico ou transcendental. Rawls não pretende alterar as doutrinas religiosas, metafísicas e morais (doutrinas compreensivas) politicamente razoáveis. Para se alcançar o razoável, são necessários dois elementos básicos: a vontade de propor termos eqüitativos de cooperação social (pessoas como livres e iguais) e o reconhecimento dos limites do juízo, tendo como conseqüência a tolerância. O liberalismo político possui três características

30 O que está em questão, para Rawls, é a elaboração de uma teoria política e não-metafísica que engloba posições universais com preocupações particulares. Esta é a interpretação de Cathérine Audard, ao analisar a autonomia doutrinal em Rawls, apontando que o trabalho do filósofo é o de construir uma teoria da justiça que seja plenamente autônoma e adaptada às condições da democracia, a fim de que os princípios de justiça sejm adotados pelos cidadãos livres e iguais, racionais e razoáveis. Ver Audard, 2004, p.21.

31 Segundo Loparic "(...) cabe reexaminar, parece-me, o sentido em que se pode continuar falando em filiação kantiana da filosofia prática de Rawls" (Loparic, 1998, p.85).

32 Ver o capítulo "L'universalisme et la diverité des peuples", em que Bertrand Guillarme analisa as características do universalismo na teoria da justiça como eqüidade rawlsiana e seu respeito pelas culturas locais e diversidade. (Guillarme, 1999, p.258-88). 
básicas: 1) aplica-se à estrutura básica da sociedade (sociedade democrática), considerando como estrutura básica as instituições políticas, econômicas e sociais, formando um sistema unificado de cooperação social; 2) pode ser formulado independentemente de qualquer doutrina compreensiva de caráter religioso, filosófico ou moral, estabelecendo uma relação através do consenso sobreposto, entre a diversas doutrinas compreensivas; 3) está baseado em idéias fundamentais como o liberalismo político, a sociedade política como um sistema eqüitativo de cooperação social, cidadãos como razoáveis, racionais, livres e iguais; sendo estas idéias, políticas e familiares a uma sociedade democrática e às suas tradições de interpretação da constituição e leis básicas (idem, p.376; $R H$ §1.1).

Seu universalismo não se fundamenta no idealismo transcendental de tipo kantiano, pois não determina a priori os seus princípios de justiça, mas dialoga entre um mecanismo de representação universal que estabelece os princípios razoáveis de justiça com a aplicação às instituições democráticas da sociedade. A posição original (original position) é um mecanismo analítico destinado a formular uma conjectura (hipótese). Quando se perguntam quais são os princípios mais razoáveis da justiça política para uma democracia, cujos cidadãos são considerados livres e iguais, razoáveis e racionais, a resposta é que estes princípios são dados por um mecanismo de representação na qual as partes racionais estão situadas em condições razoáveis e limitadas por estas condições, assim os cidadãos livres e iguais contemplam como alcançado por si mesmos um acordo sobre os princípios políticos e condições que representam aqueles cidadãos igualmente razoáveis e racionais. É apenas uma hipótese que os princípios alcançados sejam os mais razoáveis. Para Rawls, é necessário que se examine em que medida os princípios se aplicam às instituições democráticas, estabelecendo uma revisão de juízos se necessário através do equilíbrio reflexivo (reflective equilibrium) (cf. idem, p.381, 384, 388 e 389; RH §1). É possível defender a tese de que é o método do equilíbrio reflexivo que fundamenta a teoria da justiça como eqüidade de Rawls e não a posição original sob o véu da ignorância, sobretudo a partir de $P L{ }^{33}$ É importante ressaltar que essa fundamentação no equilíbrio reflexivo só tem validade para as questões de justiça social e política e não para as questões morais em geral. Este mecanismo de segurança serve para possibilitar a revisão dos princípios instituídos através do julgamento particular dos indivíduos; entretanto, são esses princípios que servem de referência para os juízos contingentes do que é o justo.

33 Norman Daniels interpreta que em $P L$, a justiça como eqüidade está baseada em um ponto de vista político independente "freestanding view", em que é possível o consenso sobreposto sobre doutrinas abrangentes. Ver Daniels, 2000, p.136-7. 


\section{Considerações Finais}

Essa interpretação da teoria da justiça como eqüidade responde às principais críticas levantadas pela interpretação comunitarista, bem como possibilita pensar em aspectos concordantes entre os liberais e os comunitaristas, visando uma concepção de justiça que integre tanto o universalismo como o particularismo. Os princípios de justiça são deontológicos (universais), porém, uma forte característica teleológica é identificada, em que o justo e o bem são interpretados como complementares, não estabelecendo uma sobreposição dos direitos individuais em relação aos direitos coletivos, mas, sim, operando com uma concepção de justiça política que reconcilia a liberdade dos modernos (autonomia privada) com a liberdade dos antigos (autonomia pública), levando em consideração as condições particulares (contingentes) de uma sociedade democrática. Não identifico na teoria da justiça como eqüidade uma concepção abstrata de pessoa, em função da utilização de uma concepção política de indivíduo que, por um lado, é considerado livre, igual e racional e, por outro, é considerado enquanto membro de uma sociedade da qual está inserido. Em razão disso, não é defensável a crítica de uma concepção individualista e atomizada de justiça política em Rawls, em que não existiria uma teoria da sociedade, existindo apenas uma atomização do social. Ressalto que não se faz necessário recorrer obrigatoriamente ao mecanismo da posição original para assegurar a validade dos princípios de justiça em uma sociedade bem-ordenada, levandose em conta de que é a própria sociedade bem-ordenada que oferece a validade a respeito dos princípios de justiça através da tradição democrática que oportuniza consensos básicos a respeito da justiça por meio do equilíbrio reflexivo (reflective equilibrium) ou do consenso sobreposto (overlapping consensus). Dessa maneira, não é apropriado apontar um subjetivismo ético liberal na teoria de Rawls, em que teríamos um Estado neutro que garantiria somente a liberdade de expressão, em função de os princípios de justiça serem utilizados como parte de uma doutrina da economia política, na qual se destaca a necessidade de efetivação da justiça com a finalidade de combater as desigualdades sociais, econômicas e políticas.

Analisada sob este prisma, a teoria de Rawls não dista consideravelmente de uma ética comunitarista, em razão de não ser verificada uma neutralidade do Estado em relação à esfera pública, em que se identifica uma inserção de substancialidade no modelo procedimental e deontológico, no qual justo e bem são evidenciados como complementares. A idéia fundamental defendida é a de uma sociedade como um sistema eqüitativo de cooperação social, o que implica a pensar nos cidadãos como livres e iguais, isto é, como membros com capacidade cooperativa e na sociedade enquanto bem-ordenada, em que todos aceitam os princípios de justiça política e 
possuem um senso de justiça. Os cidadãos estão envolvidos na cooperação social, escolhendo o pertencimento a uma comunidade moral e isso representa compreender as pessoas como livres e iguais do ponto de vista normativo, isto é, com duas faculdades morais: faculdade de ter um senso de justiça, que é a capacidade de compreender a aplicar os princípios de justiça que determinam os termos eqüitativos da cooperação e agir a partir deles e a faculdade de ter uma concepção de bem, que é a capacidade de ter, revisar e buscar alcançar uma concepção de bem de modo racional.

SILVEIRA, Denis Coitinho. John Rawls Theory of Justice: between liberalism and comunitarism. Trans/Form/Ação, (São Paulo), v.30(1), 2007, p.169-190.

- ABSTRACT: The aim of his article is to characterize the John Rawls's theory of justice as fairness developed in A Theory of Justice (1971), Political Liberalism (1993), Replay to Habermas (1995) and Justice as Fairness: A Restatement (2001), with a view to identifying the convergent points between deontological conception with teleological characteristics and identify a substantive conception of justice, not purely procedural, which is universalist albeit not transcendental, making possible an approach between communitarian and liberal ethical theories.

- KEYWORDS: justice as fairness, deontological/teleological, procedural/substantive, John Rawls.

\section{Referências bibliográficas}

AUDARD, Cathérine (Coord.). John Rawls: politique et métaphysique. Paris: PUF, 2004.

"La cohérence de la théorie de la justice". In: AUDARD, Cathérine (Coord.). John Rawls: politique et métaphysique. Paris: PUF, 2004, p.15-38.

AVINERI, Shlomo; DE-SHALIT, Avner. Communitarianism and Individualism. Oxford: Oxford University Press, 2001.

BARRY, Brian. Justice as Impartiality. Oxford: Clarendon Press, 1995.

BAYNES, Kenneth. The Normative Grounds of Social Criticism: Kant, Rawls, Habermas. Albany: SUNY Press, 1992.

CHAUVIER, Stéphane. "Biens premiers et besoins fondamentaux". In: AUDARD, Cathérine (Coord.). John Rawls: politique et métaphysique. Paris: PUF, 2004, p.63-94.

DANIELS, Norman (Ed.) Reading Rawls. 'Critical Studies on Rawls' 'A Theory of Justice'. Stanford California: Stanford University Press, 1989.

DANIELS, Norman. "Reflective equilibrium and justice as political". In: DAVION, Victoria; WOLF, Clark (Eds.) The Idea of a Political Liberalism: essays on Rawls. Lanham and Oxford: Rowman \& Littlefield Publishers, 2000, p.127-154. 
DAVION, Victoria; WOLF, Clark (Eds.) The Idea of a Political Liberalism: essays on Rawls. Lanham and Oxford : Rowman \& Littlefield Publishers, 2000.

DE VITA, Álvaro. A Justiça Igualitária e seus Críticos. São Paulo: Editora Unesp, 2000.

Justiça Liberal: argumentos liberais contra o neoliberalismo. Rio de Janeiro: Paz e Terra, 1993.

FREEMAN, Samuel (Ed.). The Cambridge Companion to Rawls. Cambridge University Press, 2003.

"Congruence and the good of justice". In: FREEMAN, Samuel (Ed.). The Cambridge Companion to Rawls. Cambridge University Press, 2003, p.277315.

GUILLARME, Bertrand. Rawls et l'Égalité Démocratique. Paris: PUF, 1999. HABERMAS, Jürgen. "Reconciliation through the public use of reason: remarks on John Rawls Political liberalism". The Journal of Philosophy, XCII, n.3, 1995.

HARSANY, J. "Can the maximin principle serve a base for morality? A critique of John Rawls's theory". American Political Science Review 69 (1995), p.594-606.

ITXASO, María Elósegui. "Comunitarismo versus Liberalismo: estado de la cuestión". Veritas, Porto Alegre, v.43, n.2, junho (1998), p.287-302.

KUKATHAS, Chandran e Philip PETTIT. Rawls: A Theory of Justice and its Critics. Oxford: Polity, 1990.

LOPARIC, Zeljko. "Sobre a interpretação de Rawls do fato da razão". In: FELIPE, Sônia T. (Org.). Justiça como Eqüidade. Florianópolis: Insular, 1998, p.73-85.

MAcINTYRE, Alasdair. After Virtue. A Study in Moral Theory. 2.ed. London: Duckworth, 1985.

MULHALL, Stephen; SWIFT, Adam. "Rawls and communitarianism". In: FREEMAN, Samuel (Ed.). The Cambridge Companion to Rawls. Cambridge: Cambridge University Press, 2003, p.460-487.

MUNOZ-DARDÉ, Véronique. La Justice Sociale: Le libéralisme égalitaire de John Rawls. Paris: Nathan, 2000.

OLIVEIRA, Nythamar F. de. Tractatus Ethico-Politicus. Porto Alegre: EDIPUCRS, 1999

POGGE, Thomas W. Realizing Rawls. Ithaca: Cornell, 1989.

"Three problems with Contractarian-Consequentialist ways of assesing social institutions". Social Philosophy and Policy, v.12, n.2 (1995).

RAMOS, Cesar Augusto. "A crítica comunitarista de Walzer à teoria da justiça de John Rawls". In: FELIPE (Org.). Justiça como Eqüidade. Florianópolis: Insular, 1998, p.231-43.

RAWLS, John. A Theory of Justice. Cambridge: Harvard University Press, 2000 (Revised Edition).

Political Liberalism. New York: Columbia University Press, 1996.

Replay to Habermas. In: Political Liberalism. New York: Columbia University Press, 1996a, p.372-434. 
RAWLS, John. Collected Papers, Ed. S. Freeman. Cambridge: Harvard University Press, 1999

Justice as Fairness: A Restatement. Edited by Erin Kelly. Cambridge: Harvard University Press, 2001.

RICOEUR, Paul. "'On John Rawls' A Theory of Justice: is a pure procedural theory of justice possible?" International Social Science Journal 42 (1990), p.553-64.

SANDEL, Michael. Liberalism and the Limits of Justice. Cambridge: Cambridge University Press, 1982.

SCANLON, T. M. "Rawls' Theory of Justice". In: DANIELS, Norman (Ed.) Reading Rawls. Stanford California: Stanford University Press, 1989, p.169-205.

SCHWARTZ, Adina. "Moral neutrality and primary goods". Ethics 83 (1973), p.294307.

TAYLOR, Charles. "Atomism". In: Philosophical Papers. 2 vol. Cambridge: Cambridge University Press, 1985, p.187-210.

"Le Juste et le Bien". Revue de Métaphysique et de Morale. Paris, anné 93, n.1, jan/mars, 1988, p.33-56.

VAN PARIJS, Philippe. "Difference Principles". In: FREEMAN, Samuel (Ed.). The Cambridge Companion to Rawls. Cambridge University Press, 2003, p.200-40.

WALZER, Michael. Spheres of Justice. Oxford: Blackwell, 1983.

WOLF, Clark. "Fundamental rights, reasonable pluralism and the moral commitments of liberalism". In: DAVION; WOLF (Eds.). The Idea of a Political Liberalism: essays on Rawls. Lanham and Oxford: Rowman \& Littlefield Publishers, 2000, p.102-26. 